\title{
THE APPEARANCE OF VESPULA SQUAMOSA DRURY IN MISSOURI
}

\section{By PhIL RaU, Kirkwood, Missouri}

Carl D. Duncan ${ }^{1}$ regards as Vespula maculifrons Buyss. the yellow jacket about which I have published two papers as Vespa germanica. ${ }^{2}$ Recently Miss Grace A. Sandhouse likewise named specimens submitted to her for examination as Vespula maculifrons.

In the spring I have always liked to watch the queens hunting for nesting sites, and for many years the clay bank in my garden, with its many crevices and old wasp and bee burrows, was a favorite hunting area. During the past three years, however, I occasionally saw searching about the clay bank a Vespula queen that differed somewhat in color from what I was accustomed to seeing. Upon submitting a specimen to Miss Sandhouse for identification, I learned that the species is Vespula squamosa Drury (=V. carolina). This I think is the first record for this wasp in Missouri.

Lewis, in his paper on "Vespinæ of the U. S. and Canada" (Trans. Amer. Ent. Soc. 24:180-181, 1897) gives its habitat under the name $V$. carolina as Pennsylvania, and under the name $V$. squamosa as New York. Turner, in his paper "The Workers of $V$. carolina resemble in Coloration the Males" (Psyche 15:1-3, 1908), records digging up a large nest at Atlanta, Georgia.

How generally $V$. squamosa is established in Missouri is not known, but at Kirkwood I am sure I have seen the queens for at least three years.

${ }^{1}$ A Contribution to the Biology of N. A. Vespine Wasps, Stanford Univ. Press, 1939.

2 "Behavior Notes on the Yellow Jacket, V. germanica" Ent. News, 41:185190, 1930, and "An Unusual Nest of the Yellow Jacket, V. germanica," Bull. Brooklyn Ent. Soc. 26:85-89, 1931. 

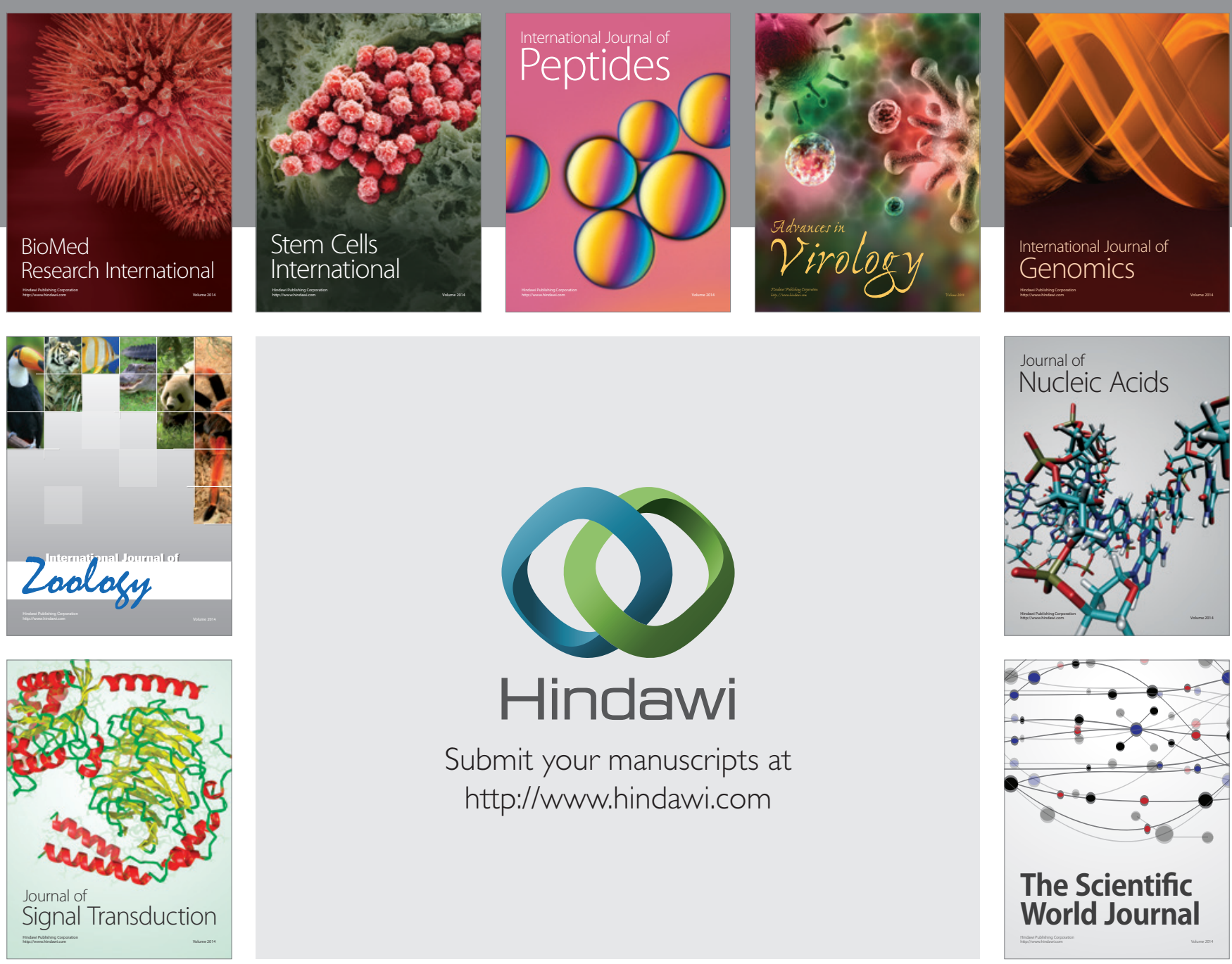

Submit your manuscripts at

http://www.hindawi.com
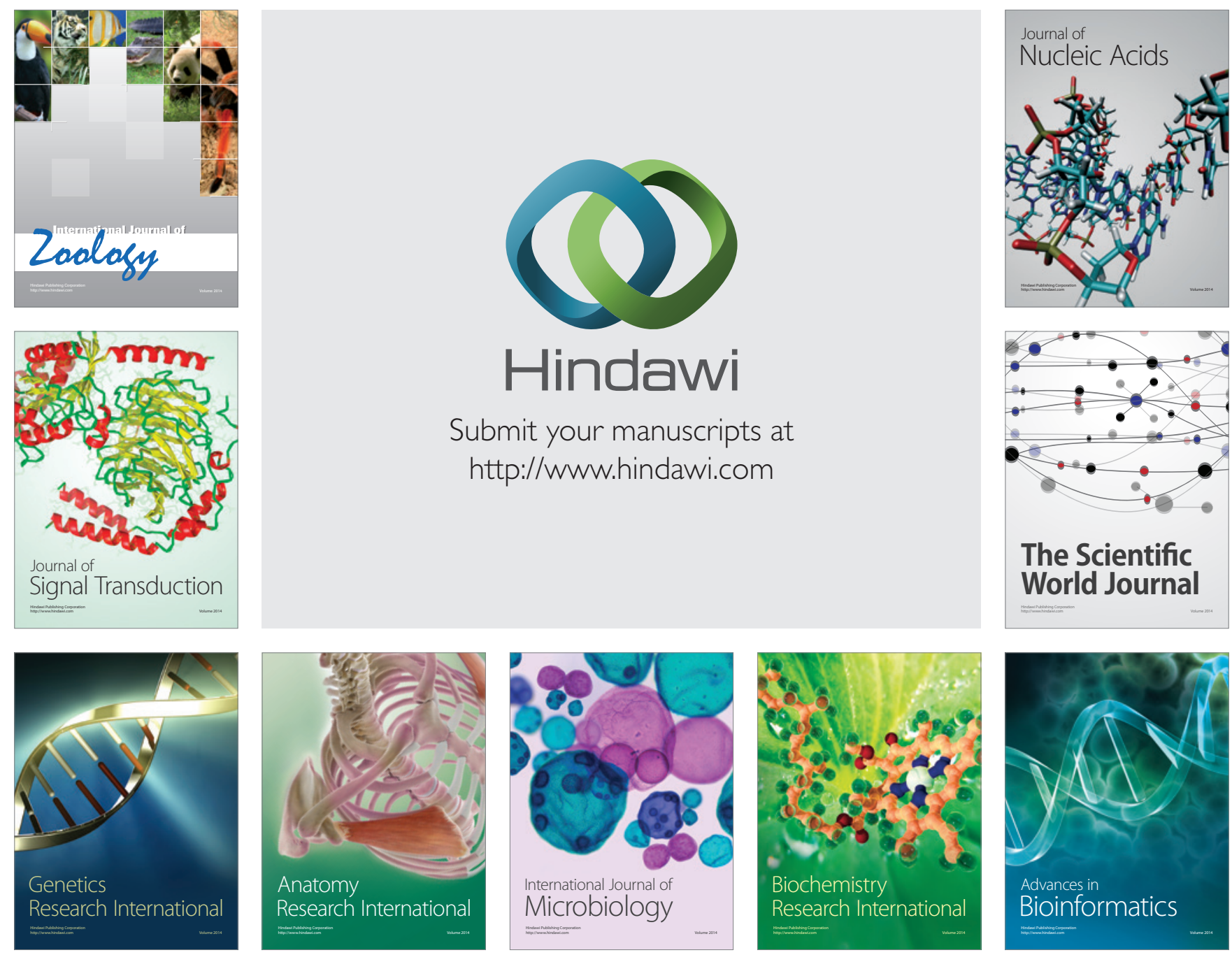

The Scientific World Journal
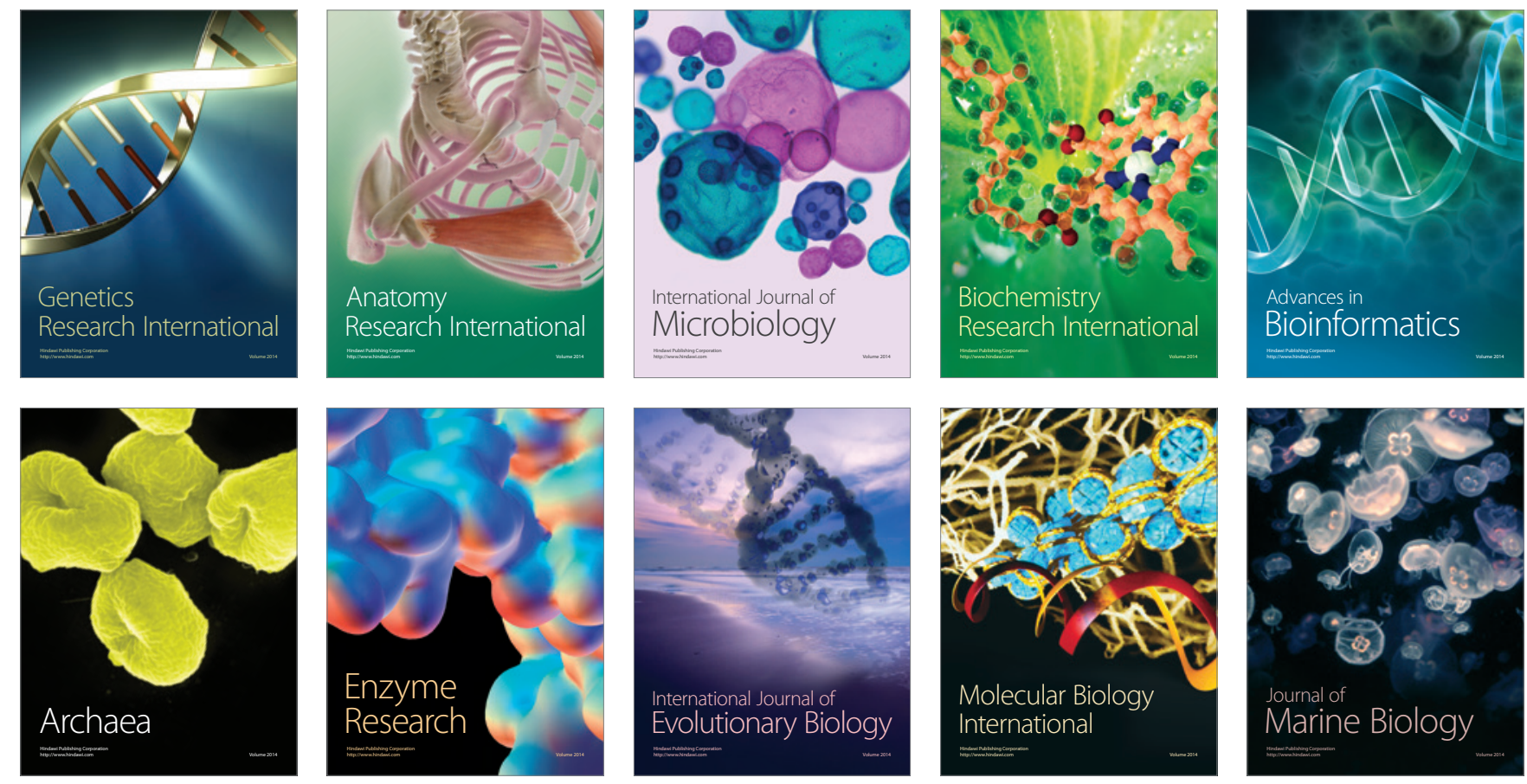